\title{
OPEN HEART SURGERY: RESULTS IN 600 CASES*
}

\author{
BY \\ HERBERT SLOAN, JOE D. MORRIS, JAMES MACKENZIE, AND AARON STERN \\ From the Department of Surgery (Section of Thoracic Surgery) and the Department of Paediatrics. \\ University of Michigan, Ann Arbor, Mich.
}

(RECEIVED FOR PUbLICATION FEBRUARY 24, 1962)

The use of extracorporeal circulation during the surgical correction of heart lesions has become generally accepted. Comprehensive discussions of the problems of open heart surgery have been published (Clowes, 1960 ; Harley, 1960 ; Allen, 1958). A variety of methods and techniques have been developed for operating on the heart under direct vision, and those that are now in wide use achieve excellent results (DeWall and Lillehei, 1962 ; Drew, 1961 ; Gerbode, Osborn, and Johnston, 1960 ; Molloy, 1961). By the end of 1961 open heart operations for acquired and congenital cardiac lesions had been performed on 600 patients at the University of Michigan Medical Center. A safe, easily controlled procedure for maintaining extracorporeal circulation has been developed which is based on a rotating disc oxygenator and a means for inducing moderate systemic hypothermia. The programme of open heart surgery began in 1957 (Sloan, Morris, vander Woude, Hewitt, and Long, 1959), and the methods now in use represent development throughout the past four years. The risk in open heart surgery to-day is related almost entirely to the severity of the cardiac lesion rather than to the use of extracorporeal circulation. The mortality rate for correction of uncomplicated cardiac defects is less than $1 \%$ in our hands.

\section{Perfusion Technique}

The equipment for extracorporeal circulation $\dagger$ consists of a receiving chamber, a rotating disc oxygenator, occlusive roller pumps for arterial perfusion and aspiration of blood from the heart, a heat exchanger, and a bubble trap (Figs. 1 and 2). There is no filter in the circuit. Tygon tubing is used to connect the elements of the extracorporeal circulation to each other and to the patient. All parts of the unit can be autoclaved. Blood is removed from the body by gravity drainage with catheters or metal cannulae placed through the right atrium into the venae cavae. The oxygenated blood is returned to

\footnotetext{
* Supported by grants from the Michigan Heart Association.

† Constructed by Edward A. Olson Co., Ashland, Mass., and Sarns, Inc., Ann Arbor, Mich.
}

the body through a metal cannula in the left superficial femoral artery.

The disc oxygenator is the result of an effort to develop an instrument combining efficiency with simplicity of design (DeWall, Grage, McFee, and Chiechi, 1962). A half cylinder seamless steel pan $8 \mathrm{~cm}$. in diameter serves as a reservoir for the blood. The pan is covered by an autoclavable plastic canopy (Lexan). The stainless steel discs, $12.5 \mathrm{~cm}$. in diameter and $0.5 \mathrm{~mm}$. in thickness, are mounted on a hexagonal shaft to prevent slipping of the discs and are separated by spacers $4.5 \mathrm{~mm}$. thick. The shaft rests on movable outboard bearing mounts attached to the ends of the oxygenator pan. Micrometer adjustment of the bearings allows the clearance between discs and pan surface to be varied during operation in order to avoid turbulence which may occur with high blood flows through the oxygenator. The outlet trap of the oxygenator is a $5 \mathrm{~cm}$. cylinder extending vertically below the pan surface; the outflow leads off at a right angle from this cylinder. A major advantage of the oxygenator design is the ease with which it can be dismantled and cleaned. Every part can be reached without difficulty. All surfaces are highly polished and both corners and seams have been eliminated.

Three sizes of oxygenators with interchangeable bearing mounts provide for adequate oxygenation in any clinical circumstance. A small oxygenator of 32 discs is employed for infants up to $10 \mathrm{~kg}$. in weight. This has been combined with a miniaturized receiving chamber and a heat exchanger having a total priming volume of $1,500 \mathrm{ml}$. The medium oxygenator of 80 discs for children and small adults is incorporated in a system having a priming volume of $3,200 \mathrm{ml}$. The adult perfusion equipment, with an oxygenator of 105 discs, requires $4,300 \mathrm{ml}$. for priming. Reserve capacity in the extracorporeal system is desirable in order to meet the sudden demands for blood which may occur during heart-lung bypass. All these units are compatible with the basic pumping unit. The small oxygenator will perform satisfactorily with flow rates up to 1.51 . per minute, the medium unit at 31 . of blood per minute, and the large unit at 5 l. per minute.

The gas mixture employed in the oxygenator is $98 \%$ oxygen and $2 \%$ carbon dioxide. Fluothane is supplied directly to the oxygenator during the per- 


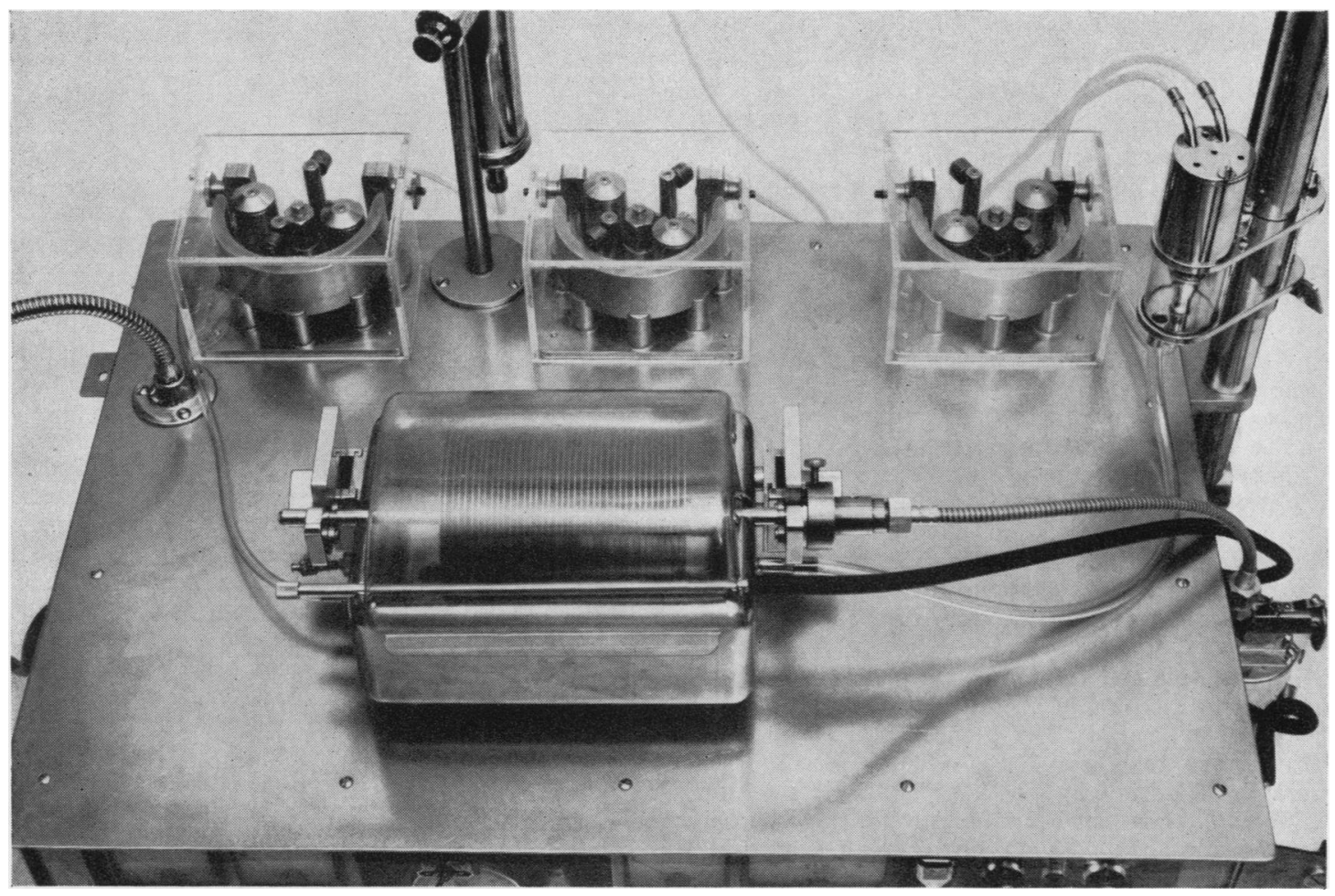

FIG. 1

FIG. 1.-Top view of extracorporeal circulation.

Fig. 2.-Extracorporeal circulation assembled for perfusion in infants with miniaturized receiving chamber, rotating disc oxygenator, and combined heat exchanger and bubble trap.

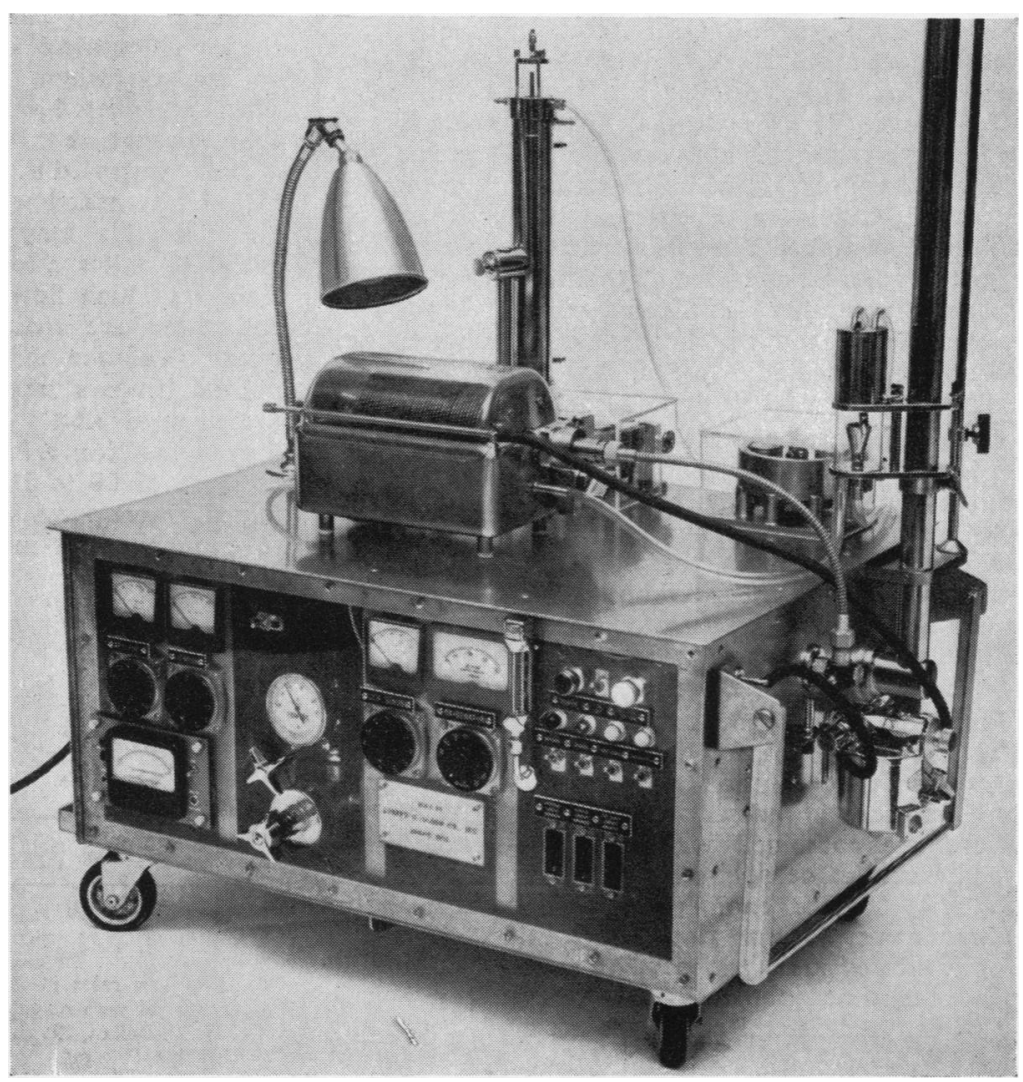

Fig. 2 
fusion from a vaporizer mounted on the side of the pumping unit. The discs are rotated at a rate of 100 revolutions per minute, but may be slowed to 80 revolutions per minute when hypothermic levels are reached.

The receiving chamber is set 20 to $30 \mathrm{~cm}$. below the patient's heart and blood is delivered from this into the oxygenator. Blood aspirated from the heart is returned to the upper portion of the receiving chamber where bubbles are removed by allowing the blood to flow over plastic sponges coated lightly with Antifoam A. A torpedo-type heat exchanger is used in the infant unit and a Brown-Harrison heat exchanger in the units for children and adults. Nylon rods are inserted in the channels of the BrownHarrison heat exchanger when the medium unit is employed to improve the efficiency of the unit and to reduce the priming volume.

Heparinized blood for the extracorporeal circuit is drawn on the morning of operation whenever possible. Some use has been made of blood drawn the preceding afternoon to which $1 \mathrm{ml}$. of $50 \%$ glucose had been added before use. Under emergency conditions ACD blood is converted for use in the extracorporeal circulation by adding $25 \mathrm{mg}$. of heparin followed by $6 \mathrm{ml}$. of $10 \%$ calcium chloride to each $500 \mathrm{ml}$. of blood (Foote, Trede, and Maloney, 1961).

The heart is exposed through a median sternotomy incision, although a right lateral thoracotomy is needed if the mitral valve is to be exposed. The venae cavae and the aorta are isolated within the pericardium. The heart is examined and a search made for additional abnormalities. Heparin in a dose of $3 \mathrm{mg}$. per $\mathrm{kg}$. of body weight is injected into the right atrium and during the perfusion an additional one-third dose of heparin is injected into the extracorporeal circuit at 45-minute intervals. The heparin is neutralized at the end of the perfusion by an equivalent amount of Polybrene (hexadimethrine), and an additional half-dose of Polybrene is given 30 minutes after the perfusion is completed.

Cannulae are placed through the right atrium into the venae cavae. The venous cannulae vary in size from an internal diameter of $4.3 \mathrm{~mm}$. for infants to $9.4 \mathrm{~mm}$. for adults. The cannula for arterial return is directed centrally in the left superficial femoral artery. A $2 \mathrm{~mm}$. arterial cannula is satisfactory for infants and graded sizes up to a $5 \mathrm{~mm}$. cannula for adults are employed. The appropriate connexions with the extracorporeal circulation are made.

Perfusion is begun on parallel and soon shifted to total heart-lung bypass. The cardiotomy is performed only when the perfusion is stable and an adequate blood pressure is maintained. The majority of perfusions are combined with moderate whole body hypothermia at oesophageal temperatures of $28^{\circ}$ to $30^{\circ}$ C. Surface cooling is started with a water mattress at the beginning of the operation. The body temperature of most patients has reached $32^{\circ}$ to $34^{\circ}$ C. by the time preparations for heart-lung bypass are made. Additional cooling is accomplished easily with the heat exchanger while the intracardiac lesion is exposed and examined. Intermittent aortic occlusion of not more than eight to ten minutes at a time is employed when necessary to improve exposure of the lesion. For more difficult operations the oesophageal temperature is lowered to $20^{\circ} \mathrm{C}$. or below, allowing periods of complete interruption of the circulation.

Rewarming with both the heat exchanger and the water mattress starts when the intracardiac repair is complete and the perfusion is discontinued at oesophageal temperatures of $35^{\circ}$ to $37^{\circ} \mathrm{C}$. and rectal temperatures of $32^{\circ}$ to $34^{\circ} \mathrm{C}$. When ventricular fibrillation occurs during hypothermia, spontaneous defibrillation is frequently seen when the blood perfusing the heart reaches a temperature of $30^{\circ} \mathrm{C}$. A single electric shock will defibrillate the heart when spontaneous defibrillation does not occur.

Moderate whole body hypothermia during perfusion has resulted in improved exposure because the pulmonary venous and coronary sinus blood returning to the heart is greatly reduced. There is also less trauma to the blood in long perfusions and the postoperative condition of the patients is improved, although this may be the result of increased experience with techniques rather than the use of hypothermia alone. Decompression of the left side of the heart has largely eliminated pulmonary congestion following perfusion. This is accomplished through an aspirating tip placed in the pulmonary artery when the right ventricle is opened, or by a sump placed in the left atrium or left ventricle. The lungs are kept half-inflated with oxygen during perfusion, but they are not ventilated.

Flow rates during perfusion are sufficient to maintain a mixed venous oxygen saturation of $70 \%$, although this may not be a valid indication of adequate oxygenation under hypothermic conditions. Relatively high flow rates are considered important, and these are maintained at two-thirds to threequarters of the minimum calculated flow rates at normal temperatures (Gollan, 1959) (Fig. 3). In the presence of aortic insufficiency or large bronchial flows, perfusion rates are increased. A mean blood pressure of 80 to $100 \mathrm{~mm}$. $\mathrm{Hg}$ is consistently maintained. Most perfusions are continued for $\mathbf{3 0}$ minutes to one hour, but in some cases the perfusions have

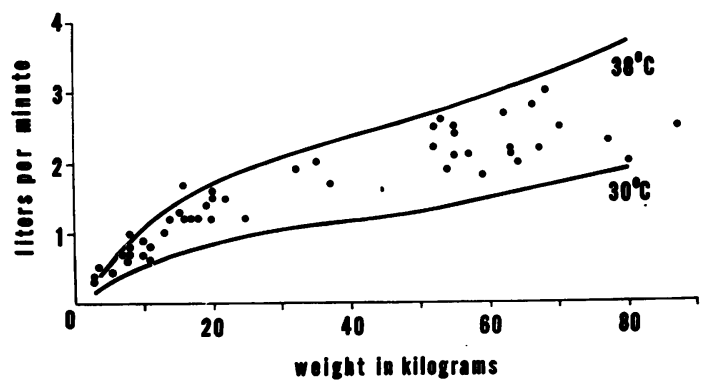

FIG. 3.-Flow rates in 50 perfusions with moderate hypothermia compared with calculated adequate perfusion rates at $30^{\circ}$ and $38^{\circ}$ C. (Gollan, 1959). 
been successfully prolonged for more than three hours.

Careful monitoring of the patient's physiological condition during the perfusion is considered essential. The electrocardiogram and electroencephalogram are recorded. Arterial and venous pressures are measured through small polyethylene catheters placed in the right femoral artery and saphenous vein. Oesophageal and rectal temperatures are recorded as well as the temperature of the arterial blood entering the patient. Oxygen saturations of arterial and mixed venous blood are determined intermittently during the perfusion.

The amount of blood introduced into the extracorporeal circulation is measured accurately and the amount remaining at the end of the perfusion is measured again. Blood lost during operation is calculated by collecting all blood aspirated by weighing sponges and by estimating blood loss on the surgical drapes. These values, together with the amount of blood administered intravenously, allow an immediate estimate of the patient's loss and replacement. This method of determining blood balance has proved satisfactory, so patients need not be weighed after operation. Venous pressures are followed carefully during and after perfusion, but continuing, accurate information about loss and replacement and careful monitoring of blood levels in the oxygenator provide more sensitive information about the blood volume of the patient before, during, and after perfusion. It is, of course, considered extremely important that the perfusion be completed with the patient's blood volume unchanged.

A large number of acid-base studies were carried out early in our experience during high flow perfusions at normal temperatures. The patients developed respiratory alkalosis combined with mild metabolic acidosis. The degree of acidosis present was comparable to that found in patients undergoing thoracic operations without perfusion, and the return to normal acid-base balance was prompt (Taylor, Theye, Devloo, and Kirklin, 1962). Similar studies have been carried out during perfusion at the

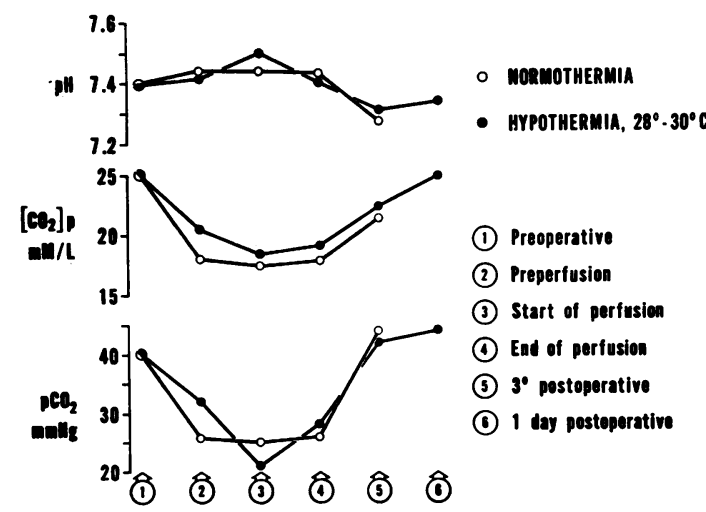

FIG. 4.-Comparison of acid-base changes during perfusions under conditions of normothermia and moderate hypothermia. temperature levels employed now, $28^{\circ}$ to $30^{\circ} \mathrm{C}$. (Fig. 4 ), and the results have been about the same when the values are corrected for the patient's temperature (Bradley, Stupfel, and Severinghaus, 1956; Trede, Foote, and Maloney, 1961). The present technique of perfusion supplies adequate amounts of oxygen to the tissues. Metabolic acidosis of significant degree does not occur and it is not necessary to add base during the perfusions.

\section{Selection of Patients}

Congenital Defects.-A congenital cardiac lesion should be repaired, if possible, whenever it poses an actual or potential threat to life which is greater than the risk entailed in surgical correction. Our experience indicates that optimum results may be expected if the patient is between 3 and 5 years old when the defect is investigated and corrected. In our series it has proved safe to carry out open heart surgery at this age. The child does not have to enter school labelled as a "cardiac" with the attendant limitation of activity and psychological trauma. More important is the fact that the earlier the defect can be corrected, the greater chance the child has to achieve his full growth potential (Engle, Holswade, Goldberg, and Glenn, 1958).

The debate about the advisability of operation to correct congenital lesions in small children has centred largely on the surgical closure of ventricular septal defects. There has been little doubt about the necessity for operation in patients with a large ventricular defect associated with markedly increased pulmonary blood flow or significant pulmonary hypertension. Many physicians believe smaller defects may safely be left alone (Lancet, 1961). Patients with little or no pulmonary hypertension in infancy do not tend to develop increasing pulmonary artery pressures during childhood, and the natural history of ventricular defects in adult life is not completely defined (Lucas, Adams, Anderson, Meyne, Lillehei, and Varco, 1961). Spontaneous closure of ventricular defects has been known to occur in rare cases, but evidence of probable closure is usually present before the infant is 2 years old as shown by a marked diminution in the intensity of the murmur and size of the heart.

It is our practice to advise closure of any ventricular defect, just as we would advise closure of a patent ductus arteriosus, believing the risks of operation to be much less than the risk of the uncorrected defect.

An important reason for correcting ventricular septal defects is the danger of subacute bacterial endocarditis. Among approximately 380 patients 
with uncorrected ventricular defects seen at the University of Michigan Medical Center, there were 19 patients who developed bacterial endocarditis. Fourteen of the patients recovered following antibiotic therapy, two patients died, and three patients had increased damage to the heart from the infection. This is considered a minimal infection rate since many of the patients were not followed after the diagnosis of ventricular defect had been established. As far as is known, there is no recorded instance of bacterial endocarditis in a surgically closed ductus arteriosus, and examination of hearts after closure of a ventricular defect has suggested that the endothelial covering of the sutures and prostheses will provide the same protection. Patients with closed ventricular defects, however, have not as yet been followed long enough to warrant the conclusion that a complicating bacterial endocarditis is impossible.

Complete heart block has not been a significant hazard of operation for ventricular defects. In our group of 194 patients with such defects, one child has a permanent heart block following closure of a ventricular defect. The child had severe pulmonary hypertension for which a previous banding procedure had been done. A second child with severe pulmonary hypertension had complete heart block and died suddenly the morning after operation. Residual left-to-right shunts are now so rare that we do not consider that the possibility of this complication should militate against a decision to close a ventricular defect.

A review of the growth patterns of children one to two years after the closure of a small ventricular defect showed graphic improvement in both height and weight in one-half of them, although the defects closed were only $3 \mathrm{~mm}$. to $6 \mathrm{~mm}$. in diameter. This was apparent in children 3 to 5 years old, but was more striking in children 6 to 12 years old.

It is surprising to hear the comments of parents whose children have undergone surgery for what was presumed to be an asymptomatic cardiac lesion. Although many of the children seemed normal before operation, the parents have described enthusiastically the increased activity their children have shown after operation.

The same indications for operation are observed in patients with such lesions as atrial septal defect and pulmonary stenosis, although the dangers of bacterial endocarditis are much less for patients with atrial defects. The mortality rate from operation in such uncomplicated congenital abnormalities has been less than $1 \%$.
It has seemed desirable to avoid operation, if possible, on children less than 2 years old. Perfusion has proved more difficult in these infants, although increasing experience has made heart-lung bypass practicable for those whose cardiac lesions require operation in order that they may survive. In our 600 patients undergoing open heart surgery, 56 were less than 2 years old. Surgery has always been considered for the child with an operable cardiac lesion when it is believed that otherwise he will not survive, but whenever possible the operation is postponed until the child has grown to a more acceptable size. However, death has occurred in some patients waiting for operation, while operation has salvaged many of these infants.

Successful open heart operations cannot be carried out on patients with severe pulmonary hypertension in whom there is a right-to-left shunt and in whom systemic flow is greater than pulmonary flow. The infant with tetralogy of Fallot who requires an operation is best treated by a shunt procedure or by infundibular resection, complete correction being postponed until a later date. When the tiny infant with pulmonary valve stenosis requires operation, a transventricular valvulotomy is done.

ACQuired Defects.-The selection of cases suitable for surgical treatment of acquired heart disease presents a greater problem. All symptomatic valvular lesions, which are multiple in many patients, deserve to be considered for correction by the open heart technique. Success or failure will be determined by the myocardial reserve present, provided improvement in valve function can be obtained by operation. The majority of these patients have mitral or aortic valve disease. Correction of all complicated mitral valve lesions under direct vision with extracorporeal circulation is now indicated, particularly when mitral insufficiency is present (Morris, Sloan, Wilson, and Brandt, 1962). Most second operations for mitral stenosis are performed with the help of heart-lung bypass. It is still our practice to employ transventricular dilatation of the mitral valve in all patients with pure, uncomplicated mitral stenosis. The use of coronary perfusion and local hypothermia during operation on the aortic valve has made careful, planned repair of aortic valve lesions possible (Kay, Nogueira, Suzuki, Postigo, and Mendelsohn, 1961).

While techniques for supporting the circulation and exposing the aortic, mitral, and tricuspid valves are available, correction of acquired heart disease is frequently more difficult than correction 
of congenital cardiac lesions. It follows that the results of operation for acquired heart disease have not been as dramatic as those for congenital heart disease. Despite this, the use of heart-lung bypass has significantly improved the results of operation for acquired heart disease, and continuing progress is being made.

\section{Problems in Post-operative Care}

The successful correction of cardiac defects with the aid of extracorporeal circulation depends as much on the care the patients receive after the operation as on the skill employed during the perfusion. In our hospital post-operative care is carried out in a unit equipped and staffed to meet the special problems of patients who have undergone a cardiac operation. A pattern of care has been developed which offers maximum support to the patient and gives prompt warning of impending complications. The problems encountered in our patients after open heart surgery have been concerned with ventilation and tracheobronchial secretions; blood and fluid replacement ; circulatory failure ; disturbances of heart rhythm; cerebral damage; disturbances of the acid-base balance; and infection and unexplained fever.

Ventilation and Tracheobronchial SecreTIONS.-Pulmonary secretions increase after open heart surgery, although pulmonary complications have become less frequent since the importance of decompressing the left side of the heart has been recognized. Recognition of retained bronchial secretions by physical examination is difficult. Portable chest radiographs, however, supply information which cannot be obtained by physical examination, and such examinations are made in the operating room and during the evening on the day of operation. Additional examinations are made on each of the next three days.

Patients are placed in an oxygen tent with high humidity. Assisted voluntary coughing is carried out at regular intervals; this has seemed more effective since the technique of median sternotomy was adopted. Intratracheal suction is a valuable aid in clearing the tracheobronchial tree. In a small child it is not possible to enter the trachea routinely, but pharyngeal stimulation usually produces effective involuntary coughing. Persistent but unsuccessful attempts to aspirate the trachea are tiring to both patient and staff and it is necessary to balance the use of this valuable adjunct against the patient's need for adequate rest. Bronchoscopy has not been employed in our cases. In infants, exposure of the larnyx and direct aspiration of the trachea with a rubbertipped sucker has been of value. Most infants and small children prefer to sleep prone or in the knee-chest position and will tolerate this procedure quite well. Every effort is made to promote bronchial drainage by this means. Tracheostomy is seldom necessary but is resorted to when secretions are not well controlled by routine means or when mechanical ventilation is necessary to maintain adequate respiratory exchange.

Blood and Fluid Replacement.-Restoration of the clotting mechanism is a fundamental requirement for successful perfusion. Polybrene (hexadimethrine) has proved a satisfactory drug for this purpose; post-operative bleeding as a result of clotting defects has been rare even after prolonged perfusions. Pre-operative bleeding, clotting, and prothrombin times are determined routinely; no other evaluation of the clotting mechanism has been necessary in this series when these values have been normal and there has been no history of bleeding.

To establish drainage the pericardium is closed loosely, the right pleural cavity opened widely, and a thoracotomy tube placed in the right pleural cavity. In some cases the pleural cavities have been left intact, the mediastinum alone being drained. When the patient is returned from the operating room his blood volume is approximately normal. Thereafter the amount of drainage from the chest is measured each half-hour; calibration of the thoracotomy jugs facilitates this measurement. The drainage fluid is replaced volume for volume by fresh whole blood. Continued rapid blood loss, particularly if undrained blood collects in the chest, is an indication for re-exploration if the clotting mechanism is normal. In the few patients who have required re-exploration inadequate haemostasis has been the most frequent cause of the bleeding. Immediate exploration of the chest with evacuation of the haematoma and control of the bleeding has been followed by astonishing improvement in the patient's condition. Drainage fluid from the chest becomes serous in 12 hours in most patients ; the volume corresponds to the drainage from a thoracic operation without a perfusion.

In our series significant anaemia has not been observed in the post-operative period. There is slight haemoconcentration in the first 48 hours which is diluted as fluid intake increases. This haemoglobin level is maintained until the patient's discharge ten days to two weeks after operation. Some adult cardiac patients with complicated 
defects have had abnormalities of blood volume before and after operation. Measurements of blood volume are helpful in the post-operative care of such patients (Carr, Sloan, and Tovar, 1960). Daily recording of the patient's weight assures recognition of fluid retention and impending heart failure in patients who are considered liable to such complications.

After operation the patient's blood pressure, pulse rate, and respiratory rate are recorded at 15-minute intervals for the first eight hours and then at decreasing intervals until the patient has returned to the open ward. Most patients have required no other special observation.

Limitation of fluid intake has contributed to the reduction in pulmonary complications (Sturtz, Kirklin, Burke, and Power, 1957). Fluid intake is based on weight rather than surface area because surface-area standards in children are not reliable (Oliver, Graham, and Wilson, 1958). The patient is allowed 40 to $55 \mathrm{ml}$. of fluid per $\mathrm{kg}$. of body weight during each of the first two 24-hour periods after the operation. The ACD solution in the citrated blood administered during and after the operation is included as part of the fluid requirement. Ice chips and small amounts of fluid are allowed by mouth on the day of operation and as much of the total fluid as the patient can tolerate is given by mouth on the day after the operation. Any deficit in fluid intake is made up by the intravenous administration of $5 \%$ glucose in $0.2 \%$ sodium chloride solution. Fluid restrictions are removed on the third postoperative day unless pre-existing heart failure makes continued limitation advisable.

Most patients void a small amount of concentrated urine on the day of operation. Diuresis occurs on the day after the operation and thereafter the urine output is normal. In our series temporary renal shutdown as a result of perfusion has been seen in three patients only.

Circulatory Failure.-The state of the patient's peripheral circulation is considered the most sensitive index of his condition after a cardiac operation. The oxygen tent, desirable as it is for providing moisture and oxygen, interferes with careful observation of the patient. A nasal catheter or face mask seems undesirable since these methods of oxygen administration make handling of pulmonary secretions more difficult and children tolerate them poorly. "Foot rounds," however, have proved to be a simple, accurate means of observing the peripheral circulation. When the feet are pink and warm and the dorsal veins of the feet filled, it seems likely that adequate oxygenation and cardiac output are being maintained by the patient. The use of indwelling catheters to follow arterial, central venous, and pulmonary artery pressures and to measure mixed venous oxygen saturation provides helpful data in patients with precarious circulatory status after operation. The measurement of central venous pressure is a sensitive index of hypovolaemia and of heart failure but is not always helpful in problems of inadequate circulation after operation.

Inadequate peripheral circulation, even with relatively good central arterial pressure, is a very grave sign. Poor circulation caused by hypovolaemia may be corrected by the administration of blood when the central venous pressure is low. Poor ventilation is occasionally the cause of failing circulation; aspiration of tracheobronchial secretions improves circulation dramatically in such cases. Inadequate peripheral circulation among our patients has usually resulted from obstruction to the flow of blood through the lungs, due either to severe pulmonary hypertension or to a mechanical block in the outflow tract of the right ventricle or in the pulmonary arteries.

Hypoxia resulting from poor peripheral circulation is followed by increasing metabolic acidosis which potentiates the circulatory failure. Assisted ventilation with the respirator and vasopressor agents may bring temporary improvement, but every effort must be made to correct the underlying abnormality. The catastrophe of sudden death after open heart surgery has occurred only in those patients with inadequate cardiac output and failing peripheral circulation.

Digitalis is not required by the majority of our patients undergoing open heart surgery. Patients with heart failure and those with severe pulmonary hypertension customarily receive digitalis before operation and the drug is always continued afterwards.

Disturbances of Heart Rhythm.-Complete heart block is a rare sequel to the repair of cardiac defects. In our experience it has never been a serious problem but has occasionally happened when cardiac arrest has been induced during the operation. In such cases the block seemed to be related to hypoxia of the heart rather than to placement of sutures close to the conduction bundle. Temporary atrioventricular dissociation has been seen frequently during bypass with hypothermia and at times has occurred before any manipulation of the heart has taken place. The condition has always cleared before completion of the operation. 
In our procedure a myocardial electrode is always inserted if complete heart block is present at the end of the operation and if the ventricular rate is too slow to maintain an adequate peripheral circulation. A transistor pacemaker maintains an adequate heart rate and circulation for these patients. Isuprel (isopropylarterenol) administered intravenously, with a change to the sublingual or rectal route of administration later, has maintained an adequate heart rate in some of these patients. In most of the few patients with complete heart block at the time of discharge cardiac rhythm has become normal within a month. In four cases the heart block continued beyond this time, resulting in the death of two of these patients.

Partial or complete right bundle branch block has been seen more frequently but has not influenced the post-operative course of our patients. In rare cases a patient with acquired heart disease has developed atrial flutter, paroxysmal atrial tachycardia, or atrial fibrillation after operation. Such disturbances of rhythm yielded to vagal stimulation, elevation of blood pressure, and administration of digitalis.

Cerebral Damage.-Air embolism as the cause of post-operative cerebral injuries in our patients has occurred only when the left side of the heart has been opened, either directly or through a septal defect. Air has thus been trapped in the left ventricle and ejected into the circulation. The perfusion apparatus itself has not been a source of air embolism.

Air embolism can be prevented by the routine aspiration of the left ventricle as soon as air can no longer enter the left side of the heart. Evacuation of the trapped air is most easily accomplished by elevating the tip of the left ventricle and aspirating the air with a syringe and needle. The patient is placed in the Trendelenburg position during perfusion so that air collects in the apex of the ventricle and cannot enter the aorta.

Neurological manifestations range from hyperexcitability and mild hallucinations immediately after operation to serious cerebral damage with focal neurological symptoms. The mild symptoms clear in a day or two; the severe symptoms persist for a week or two, but clearing has been gratifyingly complete and no patient has been left with recognized permanent damage.

The use of hypothermia in the treatment of patients with severe cerebral depression is advisable and rectal temperatures are kept at $30^{\circ}$ to $34^{\circ} \mathrm{C}$. for 72 hours by means of a water mattress.
Disturbances of the ACid-base Balance.The changes in acid-base balance after open heart surgery are similar to those seen after any thoracic operation. During operation there is respiratory alkalosis and metabolic acidosis, which change in the post-operative period when the patient is no longer overventilated to a combined respiratory and metabolic acidosis. These changes have not been of clinical importance in our series; the balance usually becomes normal within 24 hours.

If hypoxia is present or if the peripheral circulation fails, increasing metabolic acidosis occurs. Administration of sodium bicarbonate intravenously corrects the trend temporarily, but improvement can continue only when the basic cause of the acidosis is found and corrected.

INFECTION AND UNEXPLAINED FEVER.-With regard to bacterial infections, we found early in our experience that cold-sterilization of perfusion equipment was not adequate; several infections due to Pseudomonas aeruginosa occurred among our patients. All parts of the perfusion equipment that come in contact with blood are now sterilized by autoclaving, and in our last 500 open heart operations there has been only one case of infection, an overwhelming staphylococcal septicaemia. Prophylactic antimicrobial agents have been administered to all patients. The large wounds, extensive dissections, and the use of prostheses make this procedure advisable, despite conflicting opinion about the value of such prophylaxis (Linton, 1961). No serious complications accompanying the use of antimicrobial agents have been observed. No antimicrobials are applied locally during the operation, but penicillin and streptomycin are administered to the patient on the night before the operation, and this regimen, with erythromycin added, is continued for five to seven days after the operation.

Many patients are febrile for three or four days after operation with rectal temperatures ranging from $38^{\circ}$ to $39^{\circ} \mathrm{C}$. The cause of the fever has not become clear beyond the fact that it is not the result of bacterial infection. The febrile response is more prolonged in patients with large prostheses. In our post-operative care of these patients, rectal temperatures are recorded constantly. Aspirin is used freely and the oxygen tent is kept cool. For patients with temperatures of $39^{\circ} \mathrm{C}$. or higher, cooling is assisted by means of a water mattress.

\section{RESUltS}

Six hundred patients have undergone correction of congenital and acquired cardiac defects with 
the aid of extracorporeal circulation (Table I). The majority of the patients have been young children. The smallest patient successfully perfused weighed $2.5 \mathrm{~kg}$. and the largest $97 \mathrm{~kg}$. Among 311 patients with uncomplicated intracardiac defects, there were two operative deaths and one late death related to operation, for a

TABLE I

RESULTS OF EXTRACORPOREAL CIRCULATION IN 600 PATIENTS

\begin{tabular}{lrrrr}
\multicolumn{1}{c}{ Defect } & Patients & Deaths \\
\hline $\begin{array}{l}\text { Ventricular septal defect } \\
\text { No pulmonary hypertension }\end{array}$ & 141 & 194 & & 22 \\
$\begin{array}{l}\text { Pulmonary } \\
\text { Pulmonary stenosis }\end{array}$ & 53 & & 18 & \\
Atrial septal defect & & 74 & & 2 \\
Tetralogy cf Fallot & 98 & 3 \\
Aortic lesions & 86 & 16 \\
*Mitral ,y & & 56 & 8 \\
Miscellaneous & & 44 & 15 \\
& Totals & $\mathbf{6 0 0}$ & -78
\end{tabular}

* Pure uncomplicated mitral stenosis is treated by transventrizular dilatation without extracorporeal circulation.

mortality rate of less than $1 \%$. It should be noted that these deaths occurred in the first half of the group; no deaths have occurred in the last 180 of these patients.

Ventricular Septal Defects.-In 194 patients a ventricular defect was closed. Repair is customarily carried out by direct suture, although large defects are closed with a knitted Teflon prosthesis cut to the size of the defect. The ventricular defect is exposed through a longitudinal incision in the outflow tract of the right ventricle, although defects low in the muscular septum are approached more easily through an incision at the apex of the right ventricle.

Among 141 patients without serious pulmonary hypertension ( $75 \%$ of the systemic pressure) there were two early deaths and two late deaths. In one patient the cause of death was aortic regurgitation which had not been recognized before operation. In the second patient death resulted from perfusion difficulties; venous abnormalities interfered with proper cannulation. Of the two late deaths, one was due to increasing hydrocephalus, which apparently was arrested at the time of operation, and the other was due to an automobile accident.

Fifty-three of these patients had severe pulmonary hypertension with pulmonary artery pressure $75 \%$ or more of the systemic pressures. Seventeen of the patients died in the immediate post-operative period and one died later. The highest mortality occurred in patients who were 2 years of age or less and in those with insignificant left-to-right shunts or with some peripheral desaturation. The problem of caring for the patient with serious pulmonary hypertension has presented a major challenge to proponents of open heart surgery. The use of the median sternotomy, the avoidance of muscle relaxants, and the use of systemic hypothermia during perfusion, as well as fanatical attention to the avoidance of pulmonary venous congestion, have been responsible for recent improved results. Tracheostomy and assisted ventilation have been required less and less frequently.

Ten patients have had a second operation for a persistent ventricular defect. A number of patients, most of them infants, have residual murmurs of uncertain significance. In a few children with faint murmurs suggesting possible residual defects, the murmurs have disappeared in the year after operation.

Atrial Septal Defects.-Atrial septal defects of the secundum type were repaired in 84 patients. The two operative deaths in this group occurred in adult patients with severe pulmonary hypertension and peripheral arterial desaturation, conditions that are now presumed to contraindicate open heart surgery. One late death occurred when a boy who had been a patient in this group committed suicide because he was not accepted in the Armed Services.

Atrial defects are repaired by direct suture, except for large defects in adults with fragile septal tissue, which are closed with a prosthesis of knitted Teflon. Fourteen patients had partial anomalous venous drainage from the right lung entering the right atrium. In 13 it was possible to correct the defect and direct the anomalous drainage into the left atrium. In one patient a small upper lobe vein draining into the superior vena cava was allowed to remain uncorrected. In four patients pulmonic stenosis, a less important associated lesion, was corrected at the same time as the atrial defect, and in one mitral stenosis was corrected. In another patient unrecognized mitral insufficiency was repaired at a second operation.

Preliminary palpation of the atrium frequently failed to disclose the extent and the complexity of the lesions present. It was difficult to recognize by palpation the fenestrated and multiple defects. The use of heart-lung bypass enabled us to close these lesions under direct vision. It is believed that this method of closing atrial defects is superior both to blind closure and to the brief periods of exposure afforded by hypothermia.

Pulmonic STEnosis.-Pulmonary valve stenosis was corrected in 68 patients and isolated infundibular stenosis in six patients. One child was 
readmitted to the hospital eight months after operation because of a Ps. aeruginosa endocarditis of the pulmonary valve; death occurred after a prolonged hospital course. The child had been discharged from the hospital after an uneventful recovery from the operation, but since $P s$. aeruginosa was the organism found in the rare infections occurring early in our experience, the operation must be implicated in this child's death. A second patient died of pseudomembranous enterocolitis in a sanatorium where she was convalescing from resection of the left upper lobe for tuberculosis.

In the operative procedure carried out in this group, the pulmonary valve is exposed by an incision in the pulmonary artery above the valve. An attempt is made to construct a three-cusp valve by incising the stenotic valve along its commissures. Great care is taken to keep the line of incision in the commissure. Incision is carried to the annulus of the valve. Dilatation of the annulus is avoided, since this produces pulmonary valve insufficiency. No effort is made to resect the hypertrophied muscle of the outflow tract because it is believed this functional obstruction of the right ventricle gradually disappears after the pulmonary valve stenosis has been corrected (Brock, 1961). In none of the patients was there an unsuspected ventricular defect. An atrial defect was present in 18 patients and was corrected together with the pulmonic stenosis.

Tetralogy of Fallot.-Correction of tetralogy of Fallot was accomplished in 86 patients. The diagnosis of tetralogy was made when both pulmonary stenosis and a ventricular defect were present. In most cases the ventricular septal defect is closed with a prosthesis of knitted Teflon sutured in place with running sutures of $3-0$ silk. The infundibular stenosis usually present is resected as widely as possible. In the majority of patients the outflow tract is increased in size with a rectangular gusset of woven, crimped Teflon fashioned from an aortic graft (Barnard and Schrire, 1961). This is extended across the pulmonary valve as far as the left pulmonary artery whenever necessary to construct an adequate outflow tract. Twenty-two patients had previous shunts which were interrupted at the time of operation. The subclavian-pulmonary artery anastomoses were all interrupted without serious difficulty. The aorto-pulmonary artery anastomoses were more difficult to interrupt. In the majority it was possible to isolate the anastomosis and to occlude it. A procedure including deep hypothermia and circulatory arrest, with closure of the anastomosis from within the pulmonary artery, has been employed, but technical difficulties in carrying out the manœuvre were responsible for two deaths.

There were nine early deaths and three late deaths among the 64 patients without a previous shunt who underwent correction of tetralogy of Fallot. The early deaths were most frequently the result of inability to establish an adequate outflow tract. One of the late deaths was due to heart block and another to a large residual leftto-right shunt. The third death occurred suddenly and was unexplained. Among the 22 patients with a previous shunt there were four post-operative deaths.

Aortic Valve Lesions.-Correction of congenital aortic stenosis was accomplished in 22 patients ; three deaths occurred in this group, one at the time of a second operation for congenital mitral insufficiency. Congenital aortic insufficiency has been corrected in three patients without a death. Surgical correction of acquired aortic valve lesions has been much more difficult and clinical improvement after operation less satisfactory. Among nine patients operated upon for pure aortic stenosis there were two deaths. Acquired aortic insufficiency was repaired in 17 patients with six deaths. There was one death among five patients operated on for mixed aortic stenosis and insufficiency.

The heart is supported by perfusion of the left coronary artery or both coronary arteries at levels of moderate hypothermia. More recently coronary perfusion is being combined with local hypothermia by means of saline slush applied to the heart. Success in attempts to correct aortic valve lesions depends upon the protection to the heart provided during operation and upon the myocardial reserve. A second complicating problem has been the frequent presence of mitral or tricuspid valve disease which has also required correction.

Mitral Valve Lesions.-Correction of mitral valve abnormalities has been carried out through a right lateral approach in 48 patients with eight deaths. There were no deaths among the eight patients operated on for congenital mitral insufficiency. Thirteen patients underwent correction of mitral stenosis with one death. There were three deaths among the patients undergoing correction of acquired mitral insufficiency. Fourteen patients had correction of mixed stenosis and insufficiency; there were four deaths in this group. The association of aortic valve 
disease and, particularly, tricuspid valve disease has complicated correction in these patients.

Miscellaneous Lesions. - The remaining lesions were more complicated and the mortality rate was higher. There were 44 such patients and 15 did not survive operation. The lesions included transposition of the great vessels, endocardial cushion defects, and total anomalous pulmonary venous drainage.

\section{SUMMARY}

At the University of Michigan Medical Center 600 patients have undergone correction of congenital or acquired intracardiac defects with a safe, easily controlled extracorporeal circulation employing a rotating disc oxygenator and moderate systemic hypothermia. Seventy-eight early and late deaths occurred in this group of patients.

Among 311 patients with uncomplicated congenital abnormalities there have been three operative deaths, a mortality rate of less than $1 \%$. One hundred and eighty of these patients have been operated upon consecutively without a death.

Early correction of most congenital intracardiac abnormalities can be accomplished safely. We believe that the threat to the patient's life from such lesions outweighs the risk of operation.

\section{REFERENCES}

Allen, J. G., ed. (1958). Extracorporeal Circulation. Thomas, Springfield, Ill.

Barnard, C. N., and Schrire, V. (1961). Thorax, 16, 346.

Bradley, A. F., Stupfel, M., and Severinghaus, J. W. (1956). J. appl. Physiol., 9, 201.

Brock, R. (1961). Brit. Heart J., 23, 337.

Carr, E. A., Jr., Sloan, H., and Tovar, E. (1960). J. nucl. Med., 1, 165.

Clowes, G. H. A., Jr. (1960). Physiol. Rev., 40, 826.

DeWall, R. A. Grage, T. B., McFee, A. S., and Chiechi, M. A. (1962), Surgery, $\mathbf{5 1}, 251$.

- and Lillehei, C. W. (1962). J. Amer. med. Ass., 179, 430.

Drew, C. E. (1961). Brit. med. Bull., 17, 37.

Engle, M. A., Holswade, G. R., Goldberg, H. P., and Glenn, F. (1958). Pediatrics, 21, 70.

Foote, A. V., Trede, M., and Maloney, J. V., Jr. (1961). J. thorac cardiovasc. Surg., 42, 93.

Gerbode, F., Osborn, J. J., and Johnston, J. B. (1960). Thorax, 15, 185.

Gollan, F. (1959). Physiology of Cardiac Surgery. Thomas, Springfield, Iil.

Harley, H. R. S., ed. (1960). Modern Trends in Cardiac Surgery. Butterworths, London.

Kay, E. B., Nogueira, C., Suzuki, A., Postigo, J., and Mendelsohn, D. (1961). Ann. Surg., 154, Suppl., p. 159

Lancet (1961). "Ventricular septal defect" (leading article), 2. 1074.

Linton, R. R. (1961). Surg. Gynec. Obstet., 112, 218.

Lucas, R. V., Jr., Adams, P., Jr., Anderson, R. C., Meyne, N. G., Lillehei, C. W., and Varco, R. L. (1961). Circulation, 24, 1372.

Molloy, P. J. (1961). Thorax, 16, 335

Morris, J. D., Sloan, H., Wilson, W. S., and Brandt, R. L. (1962) J. thorac. cardiovasc. Surg., 43, 17.

Oliver, W. J., Graham, B. D., and Wilson, J. L. (1958). J. Amer med. Ass., 167, 1211.

Sloan, H.. Morris, J. D., vander Woude, R., Hewitt, H., and Long, G (1959). Surgery, 45, 138.

Sturtz, G. S., Kirklin, J. W., Burke, E. C., and Power, M. H. (1957) Circulation, 16, 988.

Taylor, L. M., Theye, R. A., Devloo, R. A., and Kirklin, J. W. (1962). Surg. Gynec. Obstet., 114, 97.

Trede, M., Foote, A. V., and Maloney, J. V., Jr. (1961). Ann. Surg., $154,210$. 